\title{
Some students plagiarism tricks, and tips for effective check
}

\author{
Ahmed M. Elkhatat ${ }^{1 *}$ (D) Khaled Elsaid ${ }^{2}$ and Saeed Almeer ${ }^{3}$
}

\author{
* Correspondence: ahmed.elkhatat@ \\ qu.edu.qa \\ 'Department of Chemical \\ Engineering, Qatar University, P.O. \\ 2713, Doha, Qatar \\ Full list of author information is \\ available at the end of the article
}

\begin{abstract}
One of the main goals of assignments in the academic environment is to assess the students' knowledge and mastery of a specific topic, and it is crucial to ensure that the work is original and has been solely made by the students to assess their competence acquisition. Therefore, Text-Matching Software Products (TMSPs) are used by academic institutes to ensure academic integrity and address plagiarism. However, some students find ways to trick TMSP. In this paper, files with the common tricks students do to beat $\mathrm{TMSP}_{\mathrm{S}}$ have been created and investigates with nine academic level TMPS to evaluate their effectiveness against these tricks, identifying the strengths and weaknesses of each TMSP, and providing instructors with some practical tips on checking plagiarism effectively and spotting any tricks to cheat without getting noticed.
\end{abstract}

Keywords: Plagiarism, Plagiarism tricks, Plagiarism-detection software

\section{Introduction}

Plagiarism receives increased attention after observing it in different student assignments in the academic environment, including reports, homework, projects, and many others. Academic plagiarism can be defined as using ideas, content, or structures without properly crediting the source (Fishman, 2009). This definition may extend to include all forms of intellectual properties, including images and mathematical formulas. Moreover, the definition can involve self-plagiarism, unintentional plagiarism, and plagiarism with the original author's consent (Foltýnek et al., 2020; Meuschke \& Gipp, 2013). Some students plagiarize from other students' previously submitted assignments or published resources such as web pages, journal articles, periodicals, and other publications. Students who plagiarize usually follow different approaches to plagiarize, with the extremist form when they entirely copy the source work. Other techniques include partially paraphrasing the text by changing grammar structures or words using synonyms or using some online paraphrasing services to rephrase the text (Meuschke \& Gipp, 2013; Sakamoto \& Tsuda, 2019). Besides, the translated plagiarism, converting the original text to another language to hide its origin (Roostaee et al., 2020; WeberWulff, 2010).

(c) The Author(s). 2021 Open Access This article is licensed under a Creative Commons Attribution 4.0 International License, which permits use, sharing, adaptation, distribution and reproduction in any medium or format, as long as you give appropriate credit to the original author(s) and the source, provide a link to the Creative Commons licence, and indicate if changes were made. The images or other third party material in this article are included in the article's Creative Commons licence, unless indicated otherwise in a credit line to the material. If material is not included in the article's Creative Commons licence and your intended use is not permitted by statutory regulation or exceeds the permitted use, you will need to obtain permission directly from the copyright holder. To view a copy of this licence, visit http://creativecommons.org/licenses/by/4.0/. The Creative Commons Public Domain Dedication waiver (http://creativecommons.org/publicdomain/zero/1.0/) applies to the data made available in this article, unless otherwise stated in a credit line to the data. 
The most reasons for attempting plagiarism are a shortage in understanding or lack of interest in the assignment and failing to manage the time. Other causes include students' underdeveloped sense of integrity and lack of awareness and deterrence (Brown \& Janssen, 2017; Ma et al., 2008; McCabe et al., 2001; Park, 2003).

Academic plagiarism is dishonest behavior and is considered one of the worst forms of research misconduct as it jeopardizes competence acquisition and assessment (Alsallal et al., 2013; Foltýnek et al., 2020). Hence, it is essential to mitigate it to assure academic integrity and avoid spreading this dishonest behavior into students' academic and technical careers later. Although institutes and instructors' assorted efforts to moderate the plagiarism attempts, the rapid evolution of information technology (IT) and the prevalence of vast amounts of information and data facilitate instant access and plagiarism of these sources instead of working hard to produce a genuine work (Meuschke \& Gipp, 2013). Therefore, Text-Matching Software Products (TMSPs) are considered robust tools used by academic institutes to detect plagiarism due to their sophisticated text-matching algorithm and wealthy databases that include web pages, journal articles, periodicals, and other publications. Besides, some TMSPs databases index student papers that have been submitted. Some TMSPs offer additional services such as grammar checking and proofreading. These features and capabilities of TMSPs help instructors check students' assignments for any textual plagiarism attempts.

\section{Overview of the research field}

Academic plagiarism is a very dynamic research field. Many published studies developed algorisms and codes search for the matched-texts effectively (Hajrizi et al., 2019; Pizarro and Velásquez, 2017; Roostaee et al., 2020; Sakamoto \& Tsuda, 2019; SánchezVega et al., 2013). Other studies present pedagogical tips to mitigate plagiarism among students, such as ensuring good teaching (Leask, 2006), providing workshops for students on paraphrasing arts, including academic writing skills, writing methods in their own words (Landau et al., 2016; Yang et al., 2019). Other tips include improving students' awareness of academic integrity and plagiarism (Roig, 2017), and implementing student's honor code (Coughlan, 2015).

Furthermore, the literature presents intensive reviews on plagiarism detection methods, systems, and policies (Agrawal \& Sharma, 2016; Eisa et al., 2015; Hourrane \& Benlahmar, 2017; Kanjirangat \& Gupta, 2016; Meuschke \& Gipp, 2013; Velásquez et al., 2016). A valuable systematic literature review was introduced by (Foltýnek et al., 2020a), which systematically reviewed 239 research papers published between 2013 and 2018 and introduced a three-layered conceptual model describing and comprehensively analyzing academic plagiarism phenomenon based on detection methods, systems, and policies.

Other inclusive series of studies were by The University of Applied Science, Berlin, Germany (HTW) in 2004, 2007, 2008, 2010, 2013, and 2020 to investigate the effectiveness of 15 TMSPs (HTW, 2013, 2020). The published results were quite compatible (Foltýnek et al., 2020b; Weber-Wulff et al., 2013), recommending using Turnitin, Copyscape, and Urkund. The recommendation was extended in 2020 to include PlagAware, PlagScan, and StrikePlagiarism.com. Although they did not check $i$ Thenticate, they recommended it because it uses the same database as Turnitin (Weber-Wulff et al., 2013). 
The results also included Unicheck as slightly functional software and excluded other tested 12 software for their limitations due to the false negatives, in which the system did not detect plagiarism found in the text (Foltýnek et al., 2020b). Unicheck has been integrated with Google Classroom in 2017 (UNICHECK, 2021). Another study recommends using both Blackboard-SafeAssign and Turnitin at the academic level to detect plagiarism, as the study did not find any meaningful difference between them in the effectiveness (Hunt \& Tompkins, 2014). SafeAssign is integrated with Blackboard, a virtual learning environment widely used in educational institutions, and it has an extensive repository of previously submitted assignments, scholarly journals, and web pages similar to Turnitin. SafeAssign and Turnitin have shared databases of students' papers and essays submitted through them, making their repository wealthy compared to other TMSPs.

Check-For-Plag (CFP) is another growing plagiarism detection software developed and used for plagiarism detection in Indian universities and research institutions (CFP, 2021). However, it is less recommended than Turnitin (Kumar et al., 2018).

Although all these TMSPs mentioned above can be integrated into the assignments tool in many educational institutes, some allow individuals to create accounts and submit their files to be checked as in Copyscape, PlagAware, PlagScan, StrikePlagiarism. com, Unicheck, and Check-For-Plag (CFP). However, some other TMSPs are allowed only to academic staff and students through their institutes, i.e., individuals can not create private accounts and submit their files to be checked as in SafeAssign, Turnitin, iThenticate, and Urkund.

It is noteworthy that, although the potent power of TMSPs, and the assorted efforts by researchers to improve the algorithm of the plagiarism detection software, some students found ways to trick them.

\section{Examples of common students' tricks}

Students can fool the TMSPs by different acts that hamper them from identifying the text correctly by intentionally hiding the copied text, stated as "Disguised Plagiarism" (Meuschke \& Gipp, 2013). These acts are considered the most inappropriate plagiarism acts because they are not a result of students' laziness, but students work hard and creatively to fool the system, reflecting on their potential engagement in illegal behaviors to succeed in the career. (Hodgkinson et al., 2015).

The first trick is by inserting the copied part as an image with an adjusted size in the text file before converting it to a Portable Document Format (PDF). The regular TMSPs cannot recognize Imaged-texts; hence it will not be checked, and the plagiarized part will not be reported. The second trick is inserting the plagiarized piece with unseen quotation marks (such as using white font color with a white background or minimize its font size to the minimum). Thus, the plagiarized part between these invisible quotation marks might be skipped from the plagiarism check if the option of skipping the quoted portion is applicable in the TMSPs. The third trick is replacing some letters of text with Letter-like Symbols (Unicode characters). These symbols look like regular letters, so plagiarism detectors may not identify words containing these symbols. The fourth trick replaces the spaces between words with invisible letters (i.e., g., letters with white font and smaller size). So, while the paragraph appears as separate 
words, it is one continuous word, which the plagiarism detectors cannot recognize (Campbell, 2019).

Although, to our knowledge, there are no statistical studies on students who used these tricks to fool TMSPs, the widespread of these tricks and related questions in blogs, forums, and social media can tell how students are interested in knowing ways of beating TMSPs. For example, in quora.com only, there are about 20 different question articles on how to beat plagiarism check. Each article was answered by an average of 10-15 answers and was viewed hundreds of times. Some of these tricks were highlighted as technical weaknesses, decreasing the detection accuracy in TMSPs (Meuschke \& Gipp, 2013). the plagiarism detection in texts obscured with Letter-like Symbols was emphasized by (Alvi et al., 2017) and proposed two alternative approaches to address this disguised plagiarism.

Although the highly dynamic research in the academic plagiarism field, to our knowledge, no literature compared TMSPs effectiveness against different plagiarism tricks and presented practical tips for robust plagiarism checks to moderate students' current tricks. Herein, this work investigates the effectiveness of nine academic level $\mathrm{TMSP}_{\mathrm{S}}$ against four of the popular plagiarism tricks and provides some tips to address these attempts.

\section{Methodology}

In this work, we generated five documents to be checked for plagiarism. One of these files, "Original," is 7500 words copied from a Wikipedia article and was used as a control file. Each plagiarism trick was applied in one of the other files as follow with illustrations given in Fig. 1 on how these submissions appear to the instructor:

1) "Imaged-texts": in this file, all texts were converted to images, and the file was converted to a PDF.

2) "Quoted": in this file, invisible quotation marks (white color and small size font) were inserted for all paragraphs.

3) "Letter-like Symbols": in this file, all "a" letters in words were replaced with Latin small letter alpha (Unicode- 0251) "a.," all "e" letters were replaced with Cyrillic small letter e (Unicode-0435) "e.," and all "o" letters were replaced with small Greek letter Omicron (Unicode-03BF) "o."

4) "Invisible Letters": in this file, the spaces between words were replaced with "Q" adjusted to have white color and four-sized font.

The effectiveness of nine academic level-TMSPs, including SafeAssign, Turnitin, iThenticate, Copyscape, PlagAware, PlagScan, and StrikePlagiarism.com, Unicheck, and Check-For-Plag (CFP), were tested against these plagiarism tricks. Urkund could not be tested as it is accessible only by institutes with Urkund licenses, which is not applicable in our institute. To assess the functionality of TMSPs, we consider the TMSP is functional if it could effectively detect $80-100 \%$ of the plagiarized text (shaded in green in Table 1), and partially functional if it could detect $40-80 \%$ of the plagiarized text (shaded in yellow in Table 1). However, the TMSP is considered non-functional if it could detect less than $40 \%$ of the plagiarized text (shaded in red in Table 1). 


\section{Copyright infringement}

"Pirated", "Broadcast piracy" , "Video piracy". An advertisement for copyright and patent preparation services from 1906, when copyright registration formalities were still required in the US.

Copyright infringement (referred to as piracy) is the unlawful use of works protected by copyright law without permission for a usage where such permission is required, thereby infringing certain exclusive rights granted to the copyright holder, such as the right to reproduce, distribute, display or perform the protected work, or to make derivative works. The copyright holder is typically the work's creator, or a publisher or other business to whom copyright has been assigned. Copyright holders routinely invoke legal and technological measures to prevent and penalize copyright infringement.

\section{Imaged-texts}

\section{Copyright infringement}

"Pirated", "Broadcast piracy" , "Video piracy". an advertisement for copyright and patent preparation services from 1906, when copyright registration formalities were still required in the US.

Copyright infringement (referred to as piracy) is the unlawful use of works protected by copyright law without permission for a usage where such permission is required, thereby infringing certain exclusive rights granted to the copyright holder, such as the right to reproduce, distribute, display or perform the protected work, or to make derivative works. The copyright holder is typically the work's creator, or a publisher or other business to whom copyright has been assigned. Copyright holders routinely invoke legal and technological measures to prevent and penalize copyright infringement.

Quoted

\section{Copyright infringement}

Pirated, Broadcast piracy, Video piracy. An advertisement for copyright and patent preparation services from 1906, when copyright registration formalities were still required in the US

Copyright infringement (referred to as piracy) is the unlawful use of works protected by copyright law without permission for a usage where such permission is required, thereby infringing certain exclusive rights granted to the copyright holder, such as the right to reproduce, distribute, display or perform the protected work, or to make derivative works. The copyright holder is typically the work's creator, or a publisher or other business to whom copyright has been assigned. Copyright holders routinely invoke legal and technological measures to prevent and penalize copyright infringement

\section{Invisible Letters}

\section{Copyright infringement}

"Pirated", "Broadcast piracy" , "Video piracy". An advertisement for copyright and patent preparation s ervices from 1906, when copyright registration formalities were still required in the US.

Copyright infringement (referred to as piracy) is the unlawful use of works protected by copyright law without permission for a usage where such permission is required, thereby infringing certain exclusive $r i$ ghts granted to the copyright holder, such as the right to reproduce, distribute, display or perform the $p$ rotected work, or to make derivative works. The copyright holder is typically the work's creator, or a pu blisher or other business to whomacopyright has been assigned. Copyright holders routinely invoke legal and technological measures to prevent and penalize copyright infringement.

\section{Letter-Like Symbols}

\section{Copyright infringement}

"Pirated", "Broadcast piracy", "Video piracy". an advertisement for copyright and patent preparation services from 1906, when copyright registration formalities were still required in the US.

Copyright infringement (referred to as piracy) is the unlawful use of works protected by copyright law without permission for a usage where such permission is required, thereby infringing certain exclusive rights granted to the copyright holder, such as the right to reproduce, distribute, display or perform the protected work, or to make derivative works. The copyright holder is typically the work's creator, or a publisher or other business to whom copyright has been assigned. Copyright holders routinely invoke legal and technological measures to prevent and penalize copyright infringement.

Fig. 1 Files with different plagiarism tricks 
Table 1 The effectiveness of each Text-Matching Software Products against different plagiarism tricks

\begin{tabular}{|c|c|c|c|c|c|c|}
\hline & Original & $\begin{array}{l}\text { Imaged- } \\
\text { texts }\end{array}$ & Quoted & $\begin{array}{l}\text { Letter-like } \\
\text { symbols }\end{array}$ & $\begin{array}{c}\text { Invisible } \\
\text { letters }\end{array}$ & $\begin{array}{c}\text { Imaged- } \\
\text { texts } \\
\text { (OCR) }\end{array}$ \\
\hline Blackboard-SafeAssign & $100 \%$ & $0 \%$ & $100 \%$ & $0.00 \%$ & $0.00 \%$ & $62.00 \%$ \\
\hline Turnitin & $91 \%$ & Failed & $39.00 \%$ & $91.00 \%$ & $0.00 \%$ & $90.00 \%$ \\
\hline iThenticate & $99 \%$ & Failed & $39.00 \%$ & $99.00 \%$ & $0.00 \%$ & $100.00 \%$ \\
\hline Copyscape & $99 \%$ & Failed & $99.00 \%$ & $0.00 \%$ & $0.00 \%$ & $99.00 \%$ \\
\hline PlagAware & $100 \%$ & Failed & $100.00 \%$ & $100.00 \%$ & $0.00 \%$ & $92.60 \%$ \\
\hline PlagScan & $94 \%$ & $69.8 \%$ & $26.40 \%$ & $0.00 \%$ & $59.10 \%$ & $93.80 \%$ \\
\hline StrikePlagiarism. com & $\begin{array}{c}91 \% \\
(\text { mean) }\end{array}$ & Failed & $\begin{array}{c}91 \% \\
\text { (mean) }\end{array}$ & $\begin{array}{l}55.45 \\
(\text { mean })\end{array}$ & $\begin{array}{l}81.1 \% \\
(\mathrm{mean})\end{array}$ & $\begin{array}{c}91 \% \\
\text { (mean) }\end{array}$ \\
\hline Unicheck & $98.43 \%$ & Failed & $100.00 \%$ & $2.00 \%$ & $0.00 \%$ & $100.00 \%$ \\
\hline Check-For-Plag (CFP) & $100 \%$ & $0 \%$ & $100.00 \%$ & $0.00 \%$ & $0.00 \%$ & $82.45 \%$ \\
\hline Color Index & $\begin{array}{l}\text { unctional } \\
0-100 \%)\end{array}$ & & $\begin{array}{l}\text { Parti } \\
\text { Funct } \\
(40-8\end{array}$ & & & $\begin{array}{c}\text { Non- } \\
\text { Functional } \\
(0-40 \%)\end{array}$ \\
\hline
\end{tabular}

\section{Results and discussion}

\section{The effectiveness of nine academic level-TMSPs}

The effectiveness of SafeAssign, Turnitin, iThenticate, Copyscape, PlagAware, PlagScan, and StrikePlagiarism.com, Unicheck, and Check-For-Plag (CFP) against Imaged-texts, Quoted, Letter-like symbols, and Invisible letters plagiarisms are indicated in Table 1 and Fig. 2, which reveals that all TMSPs can effectively detect the regular plagiarism copied from the Internet (Original file), as the effectivenesses of TMSPs vary between 91\%-100\%. Nevertheless, The performances of TMSPs against different plagiarism tricks differ significantly.

The performance of Blackboard-SafeAssign, Copyscape, Unicheck, and Check-ForPlag (CFP) are identical, as they are functional only against Quoted plagiarism. However, they are non-functional against Imaged-texts, Letter-like symbols, and Invisible letters plagiarisms. Hence, these TMSPs are less recommended against plagiarism tricks of interest.

The performance of Turnitin, iThenticate, and PlagAware are similar except in Quoted plagiarism. While they are functional for Letter-like symbols plagiarism, they are non-functional against Imaged-texts and Invisible letters plagiarisms. PlagAware has the advantage of detecting the Quoted plagiarism, but Turnitin and iThenticate do not. It is worth mentioning that a declamation mark appeared in Turnitin, notifying the instructor that the quoted materials are more than 30\% in the Quoted file. Furthermore, the Turnitin setting can be adjusted to include the quoted material in checking. The reason for the ability of these TMSPs to detect Letter-like symbols plagiarism is to the recently developed algorithms that can translate the characters into a readable format by giving a unique code to each character, irrespective of the alphabet format, which helps detect letter-like symbols (Hajrizi et al., 2019).

On the other hand, StrikePlagiarism.com demonstrated better performance than the previous TMSPs. In addition to its ability to detect Quoted and Letter-like symbols plagiarisms, it can also detect Invisible Letter plagiarism. However, its detection effectiveness of Letter-like symbols is less than Turnitin, iThenticate, and PlagAware. Furthermore, StrikePlagiarism.com cannot detect Imaged-texts plagiarism, and the 


\begin{tabular}{|c|c|c|c|c|}
\hline Bb slackboard & & & & \\
\hline FLENANE & FUE & MatroHNG & DRAT & SAREPORT \\
\hline$\square$ Origna.jocox & \pm & $100 \%$ & & 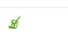 \\
\hline 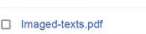 & \pm & $\%$ & & s \\
\hline 口 Invsible Leters doox & 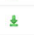 & o\% & & 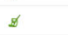 \\
\hline$\square$ audied docx & \pm & $100 \%$ & & 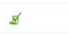 \\
\hline 口 Leterer Ilke Symmols dox & $\$$ & $0 \%$ & & a \\
\hline 口 Imagedt-exks OCR pdf & \pm & 62\% & & 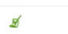 \\
\hline
\end{tabular}

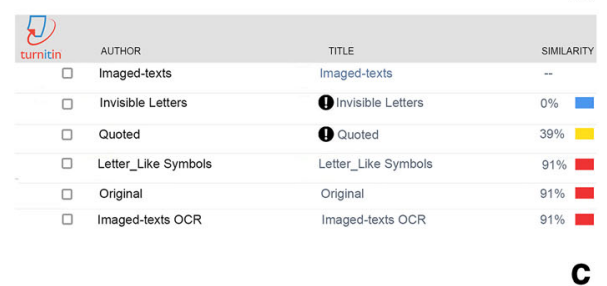

\begin{tabular}{|c|c|c|c|}
\hline$\square$ & Title & iThenticate & Report \\
\hline 0 & 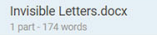 & & $0 \%$ \\
\hline$\square$ & 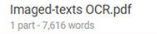 & & $90 \%$ \\
\hline$\square$ & 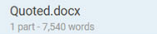 & & $39 \%$ \\
\hline$\square$ & 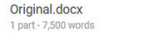 & & $99 \%$ \\
\hline व & 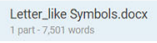 & & $99 \%$ \\
\hline
\end{tabular}

(U) UNICHECK

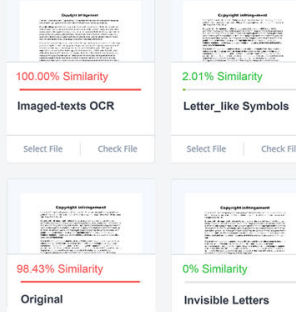

e
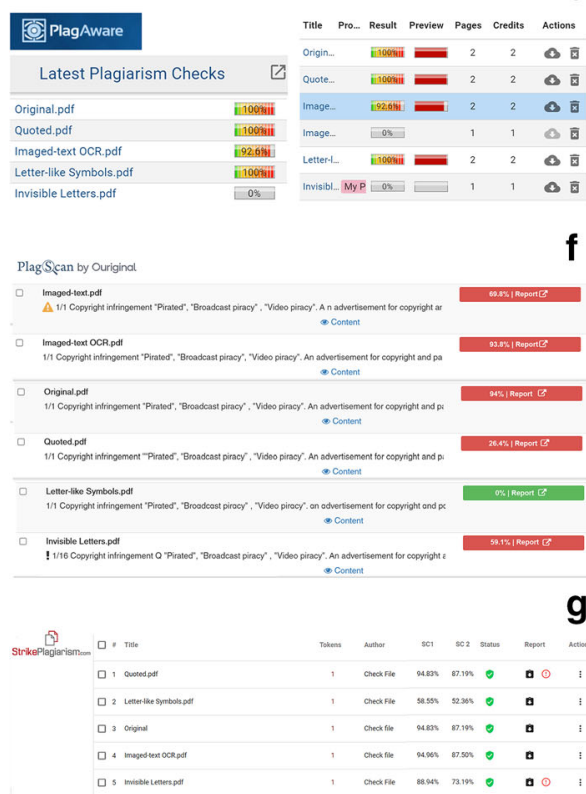

Fig. 2 Screenshots of some Text-Matching Software Products 
checking process takes about ten hours, which is a long time compared with other TMSPs that take a few minutes to show the similarity index report. It is noteworthy that PlagScan can be considered a promising TMSP. Although PlagScan is nonfunctional in detecting Letter-like symbols and quoted plagiarisms and partially functional in detecting invisible letters plagiarism, it is the only TMSP that could partially detect Imaged-texts plagiarism, reflecting developed algorithms that can translate the Imaged-texts into a readable format.

The strengths and weaknesses of each TMSP are summarized in Table 2. Accordingly, these TMSPs can be categorized into two groups, as indicated in Table 3. The first group, which is relatively functional against plagiarism tricks, includes Turnitin, iThenticate, PlagAware, PlagScan, and StrikePlagiarism.com. However, the second group that seems non-functional against plagiarism tricks includes Blackboard-SafeAssign, Copyscape, Unicheck, and Check-For-Plag (CFP).

Since Imaged-texts plagiarism seems the most challenging trick in most TMSPs, we assumed that embedding the Optical Character Recognition (OCR) technology in TMSPs might help mitigate Imaged-texts plagiarism. To assess this assumption, we used the OCR technology by image recognition integrated systems of Adobe Acrobat XI (version 11.0.23) to treat the Imaged-texts file before rechecking it with the TMSPs, and the file was given the name Imaged-texts (OCR). As shown in Table 1 and Fig. 2, the results reveal that the OCR technology, if embedded in TMSPs, will improve the TMSPs effectiveness to detect Imaged-texts plagiarism.

\section{Tips for effective plagiarism check}

Plagiarism detectors cannot detect plagiarism ultimately, and humankind inspection should be involved in the checking process. Some students intend to hide their plagiarism tricks by converting the editable file (word file) into an uneditable file (PDF),

Table 2 Summary of strength and weakness of each Text-Matching Software Products

\begin{tabular}{|c|c|c|}
\hline & Strength & Weakness \\
\hline $\begin{array}{l}\text { Blackboard- } \\
\text { SafeAssign }\end{array}$ & - Functional for Quoted plagiarism. & $\begin{array}{l}\text { - Non-functional for Imaged-texts, Letter-like sym- } \\
\text { bols, and Invisible letters plagiarisms. }\end{array}$ \\
\hline Turnitin & $\begin{array}{l}\text { - Functional for Letter-like symbols } \\
\text { plagiarism. }\end{array}$ & $\begin{array}{l}\text { - Non-functional for Imaged-texts, Quoted, and } \\
\text { Invisible letters plagiarisms. }\end{array}$ \\
\hline iThenticate & $\begin{array}{l}\text { - Functional for Letter-like symbols } \\
\text { plagiarism. }\end{array}$ & $\begin{array}{l}\text { - Non-functional for Imaged-texts, Quoted, and } \\
\text { Invisible letters plagiarisms. }\end{array}$ \\
\hline Copyscape & - Functional for Quoted plagiarism. & $\begin{array}{l}\text { - Non-functional for Imaged-texts, Letter-like sym- } \\
\text { bols, and Invisible letters plagiarisms. }\end{array}$ \\
\hline PlagAware & $\begin{array}{l}\text { - Functional for Letter-like symbols and } \\
\text { Quoted plagiarisms. }\end{array}$ & $\begin{array}{l}\text { - Non-functional for Imaged-texts and Invisible } \\
\text { letters plagiarisms. }\end{array}$ \\
\hline PlagScan & $\begin{array}{l}\text { - Partially functional for Imaged-texts } \\
\text { and Invisible letters plagiarisms. }\end{array}$ & $\begin{array}{l}\text { - Non-functional for Letter-like symbols and } \\
\text { Quoted plagiarisms. }\end{array}$ \\
\hline $\begin{array}{l}\text { StrikePlagiarism. } \\
\text { com }\end{array}$ & $\begin{array}{l}\text { - Functional for Quoted and Invisible } \\
\text { letters plagiarisms. } \\
\text { - Partially functional for Letter-like sym- } \\
\text { bols plagiarism. }\end{array}$ & $\begin{array}{l}\text { - Non-functional for Imaged-texts plagiarism. } \\
\text { - Long process time (about ten hours) }\end{array}$ \\
\hline Unicheck & - Functional for Quoted plagiarism. & $\begin{array}{l}\text { - Non-functional for Imaged-texts, Letter-like sym- } \\
\text { bols, and Invisible letters plagiarisms. }\end{array}$ \\
\hline $\begin{array}{l}\text { Check-For-Plag } \\
\text { (CFP) }\end{array}$ & - Functional for Quoted plagiarism. & $\begin{array}{l}\text { - Non-functional for Imaged-texts, Letter-like sym- } \\
\text { bols, and Invisible letters plagiarisms. }\end{array}$ \\
\hline
\end{tabular}


Table 3 Categorizing of Text-Matching Software Products against Plagiarism tricks

\begin{tabular}{ll}
\hline Non-functional TMSPs against Plagiarism tricks & Partially Functional TMSPs against Plagiarism tricks \\
\hline - Blackboard-SafeAssign & - Turnitin \\
- Copyscape & - iThenticate \\
- Unicheck & - PlagAware \\
- Check-For-Plag (CFP) & - PlagScan \\
& -StrikePlagiarism.com \\
\hline
\end{tabular}

preventing humankind inspection for any inappropriate imaged texts, quotation marks, hidden letters, or letter-like symbols. In other words, those students use PDF files as camouflage to pass their tricks.

Receiving the assignments in an editable file helps instructors catch these improper attempts, especially the imaged texts, quoted and invisible letters plagiarisms, which are the most challenging tricks. For example, in the editable file, the Imaged-texts become apparent to the instructor as pictures, not texts. Furthermore, the editable file helps the instructor unify the file format, including font color and size, to catch any inappropriate quotation marks, hidden letters, or letter-like symbols. For example, unifying the file format to be black and 11 font size font will expose all invisible white letters, invisible tiny or white quotations, as shown in Fig. 3.

\title{
Invisible Letters
}

\section{CopyrightQinfringement}

"Pirated",Q"BroadcastQpiracy"Q,Q"VideoQpiracy".QQAnQadvertisementQforQcopyrightQand QpatentQpreparationQservicesQfromQ1906,QwhenQcopyrightQregistrationQformalitiesQwere QstillQrequiredQinQtheQUS.

CopyrightQinfringementQ(referredQtoQasQpiracy)QisQtheQunlawfulQuseQofQworksQprotect edQbyQcopyrightQlawQwithoutQpermissionQforQaQusageQwhereQsuchQpermissionQisQreq uired,QtherebyQinfringingQcertainQexclusiveQrightsQgrantedQtoQtheQcopyrightQholder, Qsu chQasQtheQrightQtoQreproduce,Qdistribute,QdisplayQorQperformQtheQprotectedQwork,Qor QtoQmakeQderivativeQworks.QTheQcopyrightQholderQisQtypicallyQtheQwork'sQcreator,Qor QaQpublisherQorQotherQbusinessQtoQwhomQcopyrightQhasQbeenQassigned.QCopyrightQh oldersQroutinelyQinvokeQlegalQandQtechnologicalQmeasuresQtoQpreventQandQpenalizeQco pyrightQinfringement.

\section{Quoted}

\section{Copyright infringement}

\begin{abstract}
"'Pirated", "Broadcast piracy" , "Video piracy". An advertisement for copyright and patent preparation services from 1906, when copyright registration formalities were still required in the US".

"Copyright infringement (referred to as piracy) is the unlawful use of works protected by copyright law without permission for a usage where such permission is required, thereby infringing certain exclusive rights granted to the copyright holder, such as the right to reproduce, distribute, display or perform the protected work, or to make derivative works. The copyright holder is typically the work's creator, or a publisher or other business to whom copyright has been assigned. Copyright holders routinely invoke legal and technological measures to prevent and penalize copyright infringement".
\end{abstract}

Fig. 3 Invisible letters and quoted files after instructor unify the file format, including font color and size 
Hence, instructors should specify the file submission format by restricting the acceptable file format to editable files, such as word or relatives. Although most plagiarism detection software allows checking PDF files, students can beat them, as discussed earlier. Thus, PDF files should be avoided. Clear instructions should be given to students concerning file submission well ahead, either as part of the syllabus or as part of the assignment statement.

\section{Conclusion}

Although the potent power of TMSPs, and the researchers' efforts to improve the algorithm of the plagiarism detection software, some students found ways to trick them. These students' acts are considered the most inappropriate plagiarism acts because they are not due to students' laziness. In contrast, students work hard and creatively to fool the system, reflecting on their potential engagement in illegal behaviors to succeed in the career. Although the effectiveness of TMSPs in detecting regular plagiarism, their performances against different plagiarism tricks vary significantly, and each one has its strengths and weaknesses. According to the TMSPs performance against plagiarism tricks, they can be categorized into relatively functional and non-functional TMSPs. The functional TMSPs category includes Turnitin, iThenticate, PlagAware, PlagScan, and StrikePlagiarism.com. On the other hand, the non-functional TMSPs category includes Blackboard-SafeAssign, Copyscape, Unicheck, and Check-For-Plag (CFP). The study recommends embedding the OCR technology in TMSPs, to improve their effectiveness against Imaged-texts plagiarism. Besides, instructors should specify the file submission format by restricting the acceptable file format to editable files, such as word or related, to help catch any improper attempts for textual plagiarism.

\section{Abbreviations}

HTW: The University of Applied Science, Berlin, Germany; OCR: The Optical character recognition; PDF: Portable Document Format; TMSP: Text-Matching Software Products

\section{Supplementary Information}

The online version contains supplementary material available at https://doi.org/10.1007/s40979-021-00082-w.

Additional file 1.

Acknowledgements

The publication of this article was funded by the Qatar National Library.

Authors' contributions

Ahmed M. Elkhatat: First Draft, Conducting the experiments, discussing the results. Khaled Elsaid: Second Draft, Validate the concepts, and contributing to the discusssion. Saeed Almeer: Final version, Proofreading, and improving the discussion. The authors read and approved the final manuscript.

\section{Funding}

The publication of this article was funded by the Qatar National Library according to Springer Nature and Qatar National Library have an active Open Access agreement. Open Access funding provided by the Qatar National Library. https://www.springernature.com/gp/librarians/open-research-for-librarians/sn-oa-agreements/qatar

Availability of data and materials

All data and materials are available.

\section{Declarations}

Competing interests

The authors declare that they have no conflict of interest. 


\section{Author details}

${ }^{1}$ Department of Chemical Engineering, Qatar University, P.O. 2713, Doha, Qatar. ${ }^{2}$ Texas A\&M University at Qatar, Chemical Engineering Program, P.O. 23874, Doha, Qatar. ${ }^{3}$ Department of Chemistry and Earth Sciences, Qatar University, P.O. 2713, Doha, Qatar.

Received: 21 February 2021 Accepted: 2 June 2021

Published online: 27 July 2021

\section{References}

Agrawal M, Sharma DK (2016) A state of art on source code plagiarism detection. In: Paper presented at the 2016 2nd international conference on next generation computing technologies (NGCT)

Alsallal M, labal R, Amin S, James A (2013) Intrinsic Plagiarism Detection using Latent Semantic Indexing and Stylometry. In: Paper presented at the 2013 sixth international conference on developments in eSystems engineering

Alvi F, Stevenson M, Clough P (2017) Plagiarism Detection in Texts Obfuscated with Homoglyphs. In: Paper presented at the Advances in Information Retrieval, Cham: White Rose Research Online https://eprints.whiterose.ac.uk/

Brown N, Janssen R (2017) Preventing plagiarism and fostering academic integrity: a practical approach. J Perspect Appl Acad Pract 5(3):102-109

Campbell, A. (2019). Can Students Trick Turnitin? Retrieved from https://www.turnitin.com/blog/can-students-trick-turnitin

CFP, C.-F.-P. (2021). Check-For-Plag: A unique MAKE IN INDIA Initiative to curb plagiarism globally. Retrieved from https:// www.checkforplag.com/about

Coughlan, S. (2015). Harvard students take pledge not to cheat. Retrieved from http://www.bbc.co.uk/news/business-3476943

Eisa TAE, Salim N, Alzahrani S (2015) Existing plagiarism detection techniques: a systematic mapping of the scholarly literature. Online Inf Rev 39(3):383-400. https://doi.org/10.1108/OIR-12-2014-0315

Fishman T (2009) "We know it when we see it" is not good enough: toward a standard definition of plagiarism that transcends theft, fraud, and copyright. In: Paper presented at the 4th Asia Pacific conference on educational integrity. University of Wollongong NSW, Australia

Foltýnek T, Dlabolová D, Anohina-Naumeca A, Razı S, Kravjar J, Kamzola L, Guerrero-Dib J, Celik Ö, Weber-Wulff D (2020a) Testing of support tools for plagiarism detection. Int J Educ Technol High Educ 17(1). https://doi.org/10.1186/s41239-02000192-4

Foltýnek T, Meuschke N, Gipp B (2020) Academic plagiarism detection. ACM Comput Surv 52(6):1-42. https://doi.org/10.114 $5 / 3345317$

Hajrizi E, Zylfiu B, Menxhiqi L (2019) Developing a system for detecting the same content within the UBT academic institution, including special characters. IFAC-PapersOnLine 52(25):264-268. https://doi.org/10.1016/j.ifacol.2019.12.493

Hodgkinson T, Curtis H, MacAlister D, Farrell G (2015) Student academic dishonesty: the potential for situational prevention. J Crim Justice Educ 27(1):1-18. https://doi.org/10.1080/10511253.2015.1064982

Hourrane O, Benlahmar EH (2017) Survey of plagiarism detection approaches and big data techniques related to plagiarism candidate retrieval. In: Paper presented at the proceedings of the 2 nd international conference on big data. Cloud and Applications, Tetouan. https://doi.org/10.1145/3090354.3090369

HTW, U. o. A. S. (2013). Results of the Plagiarism Detection System Test 2013. Retrieved from https://plagiat.htw-berlin.de/ software-en/test2013/

HTW, U. o. A. S. (2020). Results of the Plagiarism Detection Support Tool Test 2020. Retrieved from https://plagiat.htw-berlin de/software/softwaretest-2020/

Hunt J, Tompkins P (2014) A comparative analysis of SafeAssign and Turnitin. Inquiry 19(1):63-73

Kanjirangat V, Gupta D (2016) Study on extrinsic text plagiarism detection techniques and tools. J Eng Sci Technol Rev 9(5):923

Kumar N, Gaur R, Singh V, Dutt S (2018) Awareness among research scholars towards Turnitin: a study of guru Jambheshwar University of science \& technology Hisar, Haryana. Library Progress Library Sci Inform Technol Comp 38(2):191-198

Landau JD, Druen PB, Arcuri JA (2016) Methods for helping students avoid plagiarism. Teach Psychol 29(2):112-115. https:// doi.org/10.1207/s15328023top2902 06

Leask B (2006) Plagiarism, cultural diversity and metaphor_-implications for academic staff development. Assess Eval High Educ 31(2):183-199. https://doi.org/10.1080/02602930500262486

Ma HJ, Wan G, Lu EY (2008) Digital cheating and plagiarism in schools. Theory Pract 47(3):197-203. https://doi.org/10.1080/ 00405840802153809

McCabe DL, Trevino LK, Butterfield KD (2001) Cheating in academic institutions: a decade of research. Ethics Behav 11(3):219232. https://doi.org/10.1207/s15327019eb1103_2

Meuschke N, Gipp B (2013) State-of-the-art in detecting academic plagiarism. Int J Educ Integr 9(1). https://doi.org/10.21913/ IJEl.v9i1.847

Park C (2003) In other (People's) words: plagiarism by university students--literature and lessons. Assess Eval High Educ 28(5): 471-488. https://doi.org/10.1080/02602930301677

Pizarro VG, Velásquez JD (2017) Docode 5: building a real-world plagiarism detection system. Eng Appl Artif Intell 64:261-271. https://doi.org/10.1016/j.engappai.2017.06.001

Roig M (2017) Can undergraduate students determine whether text has been plagiarized? Psychol Rec 47(1):113-122. https:// doi.org/10.1007/bf03395215

Roostaee M, Sadreddini MH, Fakhrahmad SM (2020) An effective approach to candidate retrieval for cross-language plagiarism detection: a fusion of conceptual and keyword-based schemes. Inf Process Manag 57(2):102150. https://doi. org/10.1016/j.ipm.2019.102150

Sakamoto D, Tsuda K (2019) A detection method for plagiarism reports of students. Proc Comp Sci 159:1329-1338. https:// doi.org/10.1016/j.procs.2019.09.303

Sánchez-Vega F, Villatoro-Tello E, Montes-y-Gómez M, Villaseñor-Pineda L, Rosso P (2013) Determining and characterizing the reused text for plagiarism detection. Expert Syst Appl 40(5):1804-1813. https://doi.org/10.1016/j.eswa.2012.09.021 
UNICHECK. (2021). Plagiarism prevention tool that encourages critical thinking. Retrieved from https://unicheck.com/plagia rism-detection-solution

Velásquez JD, Covacevich Y, Molina F, Marrese-Taylor E, Rodríguez C, Bravo-Marquez F (2016) DOCODE 3.0 (DOcument COpy DEtector): a system for plagiarism detection by applying an information fusion process from multiple documental data sources. Inform Fusion 27:64-75. https://doi.org/10.1016/j.inffus.2015.05.006

Weber-Wulff D (2010) Test cases for plagiarism detection software. In: Paper presented at the the 4th international plagiarism conference, Newcastle upon Tyne

Weber-Wulff, D., Möller, C., Touras, J., \& Zincke, E. (2013). Plagiarism detection software test 2013. Retrieved from https://plagia t.htw-berlin.de/software-en/test2013/report-2013/

Yang A, Stockwell S, McDonnell L (2019) Writing in your own voice: an intervention that reduces plagiarism and common writing problems in students' scientific writing. Biochem Mol Biol Educ 47(5):589-598. https://doi.org/10.1002/bmb.21282

\section{Publisher's Note}

Springer Nature remains neutral with regard to jurisdictional claims in published maps and institutional affiliations.

- fast, convenient online submission

- thorough peer review by experienced researchers in your field

- rapid publication on acceptance

- support for research data, including large and complex data types

- gold Open Access which fosters wider collaboration and increased citations

- maximum visibility for your research: over $100 \mathrm{M}$ website views per year

At $\mathrm{BMC}$, research is always in progress. 